http://jmscr.igmpublication.org/home/ ISSN (e)-2347-176x ISSN (p) 2455-0450

crossref DOI: https://dx.doi.org/10.18535/jmscr/v9i8.19

\author{
(D) Journal Of Medical Science And Clinical Research \\ IGM Publication \\ An Official Publication of IGM Publication
}

\title{
Establishing Flow Velocity of the Common Carotid Artery in Normal adults Using Ultrasonography
}

\author{
Authors \\ Annongu IT, ${ }^{1 *}$ Magaji OG, ${ }^{2}$ Chia DM, ${ }^{1}$ Hameed M, ${ }^{1}$ Abubakar F, ${ }^{3}$ \\ Angbalaga $\mathrm{A}^{2}{ }^{2}$ Bulus $\mathbf{P U}^{2}$ \\ ${ }^{1}$ Department of Radiology, College of Health Sciences, Benue State University Makurdi \\ ${ }^{2}$ Department of Radiology, Dalhatu Araf Specialist Hospital, Lafia, Nassarawa state \\ ${ }^{3}$ Department of Radiology, College of Medical Sciences, University Of Maiduguri, Borno \\ State \\ *Corresponding Author \\ Dr Annongu Isaac Terkimbi \\ Department of Radiology, College of Health Sciences, Benue State University Makurdi
}

\section{Introduction}

The ability to assess and monitor total cerebral blood flow volume (tCBFV) is clinically important particularly in patients with cerebrovascular disorders, serious head trauma, and increased intracranial pressure. Increased intracranial pressure which is a common condition in neurologic intensive care units and reducing tCBFV is among the therapeutic alternatives, ${ }^{1}$ ${ }^{2}$ The prevalence of atherosclerosis, ischemia, infarction, and neurodegenerative disorders increases with age and causes impairment in cerebral perfusion hence, the age-dependent changes in tCBFV should be understood and considered. ${ }^{3}$

Extracranial carotid artery disease is responsible for more than $50 \%$ of all the cerebrovascular disorders. ${ }^{4}$ Flow limiting stenosis of the carotid artery is a common predisposing cause of cardiovascular diseases including stroke. There is crucial age, body habitus and gender-related differences in the prevalence and burden of cardiovascular disease ${ }^{5}$. An approach to understanding this disparity particularly in stroke is to establish normal characteristic profile of carotid flow velocities. Ultrasonography which is a non-invasive, safe and relatively inexpensive technique devoid of ionizing radiation is increasingly used for evaluation of flow velocities thus detecting early atherosclerosis changes and predicting clinical complications. ${ }^{6}$

The main goal of this study was therefore to assess blood flow velocity and waveform parameters, of the CCAs in healthy adults using ultrasound and to evaluate its relationship with sex, body mass index (BMI) and as well as its age-dependent changes.

\section{Methods}

This prospective study was conducted on apparently healthy adult 18 years and above from a Teaching Hospital in north eastern Nigeria. Volunteers were recruited consecutively at random from the neighboring tertiary schools and 
within the hospital. Excluded were volunteers with past historyorat risk of cardiovascular disease, currently smoking, pregnant women, individuals on drugs such as opiates or those that consume alcohol. Also those with major anatomic variations of the common carotid arteries were excluded.

Informed written consent was obtained from the subjects before enlistment into the study. Approval to carry out the study was obtained from the Ethical Committee of the institution.

At recruitment, Clinical parameters which include age, sex and height in meters and weight in kilograms were recorded. The BMI was calculated as a ratio of the measured weight to square of the measured height $(\mathrm{kg} / \mathrm{m} 2)$. BMI of $<18.50$ was categorised as underweight, 18.50-24.99 as normal and 25.00-29.99 as overweight.

The examinations were performed using a highresolution real-time Doppler ultrasound scanner (Aloka, SSD-3500) equipped with $7.5 \mathrm{MHz}$ linear-array transducer. The $7.5 \mathrm{MHz}$ linear-array transducer provides greater resolution for superficial structures such as the carotid artery.

In a supine position, the patient's shoulder was placed on pillow with the neck extended and turned slightly away from the side being scanned. After applying ultrasound gel to the neck, the transducer was placed above the clavicle first in a transverse projection for the grey-scale examination. The CCA was located and followed proximally as far as the clavicle permitted to the level of the carotid bifurcation (thyroid cartilage). Longitudinal views were similarly obtained.

Doppler interrogation of the CCA was performed in the longitudinal plane using angle $<60^{\circ}$. Spectral Doppler waveform was obtained at proximal, middle and distal portions. The PSV and EDV were determined from velocity waveforms at all locations obtained.

The data obtained from the structured data sheet was entered into a computer system. Analysis was performed with statistical package for social science software (SPSS version 16.0 Chicago, IL, USA). The results were expressed as mean \pm standard deviation (SD) and presented in the form of tables, charts and graphs as appropriate. Statistical significance was assessed using students' test to compare the mean flow velocities between two sexes. Correlation between the CCA flow velocities with height, weight and BMI were evaluated using Pearson's correlation test. Simple linear regression was used to correlate patient age and sex with CCA flow velocities. $\mathrm{P}$ value $<0.05$ was considered statistically significant.

\section{Results}

Four hundred volunteers participants in the study: 239 (59.80\%) males, 161 (40.20\%) females. Ages ranged between 18 and 81 years (Mean $=36.74 \pm$ 14.79 years). The mean age range was $37.18 \pm 15.08$ and $3608 \pm 14.37$ for males and females respectively. Majority of the subjects $\{148(37 \%)\}$ were in the age group 21 to 30 years consisting of $62(15.50 \%)$ females and 86 (21.50\%) males (Table 1)

Table 2 shows the relationship between the mean body parameters and age group. All body parameters were high in the age group 41-50 years. Their heights ranged between $1.50-1.90 \mathrm{~m}$ $($ Mean $=1.67 \pm 0.75 \mathrm{~m})$. The least height $(1.62 \pm$ $0.11 \mathrm{~m}$ ) was recorded in the age group $61-70$ years. Weight ranged between 40-96kg (Mean = $63.82 \mathrm{~kg} \pm 9.87)$ and the body mass index $(\mathrm{BMI})$ from $15.10-37.50$ (Mean $=22.87 \pm 3.26)$. The least BMI was in the aged group 81-90 years $(20.40 \pm 0.00)$.

The relationship between sex and mean of body parameters is shown in table 3. All body parameters were lower in females.

In tables $4 \& 5$, the mean PSV and EDV OF CCA of different age groups for males and females subjects respectively has been shown. The highest mean \pm SD PSV for CCA was in the age group of 20years and below and the lowest in the age group $>70$ years. Similar observation was seen for EDV of CCA.

Table 6shows the overall mean PSV and EDV values on the right and left sides of subjects. A trend in PSV was observed along the course of the 
CCA. The more distal the measurement, the lower the velocity (Table 7). There was no correlation between the ranges of PSV in the CCA on the left and the right sides ( $\mathrm{r}=0.09$ ).

In contrast, EDV values increased along the course of the CCA. The average right proximal CCA EDV was $14.20 \mathrm{~cm} / \mathrm{sec} \pm 4.30$ compared with the average distal CCA EDV of $19.70 \mathrm{~cm} / \mathrm{sec}$ $\pm 3.80(\mathrm{p}=0.000)$. No significant statistical difference was seen between the right and left CCA PSV: $\mathrm{t}=1.150, \mathrm{P}=0.251$.

Table: 8 showed the average mean velocities of CCA with different age group in the study population. There was decrease in the mean values of both the PSV and EDV in the CCA with respect to age and was statistically significant. Table 9 summarised the average mean CCA blood velocities for males and females in the study population.

Tables 10 and 11 show the relationship of BMI with PSV and EDV. The mean total PSV was lower in the overweight individual than the normal and the underweight individuals in both males and females, similar findings were seen in the mean total EDV and this was statistically significant.

Table 1: Age group and sex distribution

\begin{tabular}{|c|c|c|c|}
\hline Age group (years) & Males N (\%) & Females N (\%) & Total N (\%) \\
\hline$\leq 20$ & $20(5.00)$ & $12(3.00)$ & $32(8.00)$ \\
\hline $21-30$ & $86(21.50)$ & $62(15.50)$ & $148(37.00)$ \\
\hline $31-40$ & $57(14.25)$ & $42(10.50)$ & $99(24.75)$ \\
\hline $41-50$ & $29(7.25)$ & $12(3.00)$ & $41(10.25)$ \\
\hline $51-60$ & $25(6.25)$ & $20(5.00)$ & $45(11.25)$ \\
\hline $61-70$ & $14(3.50)$ & $11(2.75)$ & $25(6.25)$ \\
\hline $71-80$ & $6(1.50)$ & $2(0.50)$ & $8(2.00)$ \\
\hline $81-90$ & $2(0.50)$ & $0(0.00)$ & $2(0.50)$ \\
\hline Total & $239(59.80)$ & $161(40.20)$ & $400(100)$ \\
\hline
\end{tabular}

Table 2: Mean body parameters in each age group.



BMI: body mass index.

SD: standard deviation.

$\mathrm{N}$ : sample population.

Table 3: Sex and overall mean body parameters (height, weight, and BMI)

\begin{tabular}{|l|c|c|c|}
\hline Sex(N) & $\begin{array}{c}\text { Height }(\mathrm{m}) \\
\text { Mean } \pm \text { SD }\end{array}$ & $\begin{array}{c}\text { Wight }(\mathrm{kg}) \\
\text { Mean } \pm \text { SD }\end{array}$ & $\begin{array}{c}\text { BMI }\left(\mathrm{KG} / \mathrm{M}^{2}\right) \\
\text { Mean } \pm \mathrm{SD}\end{array}$ \\
\hline Male (239) & $1.70 \pm 0.67$ & $66.03 \pm 9.93$ & $22.86 \pm 3.26$ \\
\hline Female(161) & $1.63 \pm 0.67$ & $60.54 \pm 8.8$ & $16.31 \pm 0.66$ \\
\hline
\end{tabular}

BMI: body mass index

SD: standard deviation.

$\mathrm{N}$ : sample population. 
Table 4: Mean CCA and ICA PSV and EDV of different age groups males

\begin{tabular}{|l|c|c|c|c|c|c|c|}
\hline PSV $(\mathbf{c m} / \mathbf{s})$ & $\begin{array}{c}\leq \mathbf{2 0 y e a r s} \\
\mathbf{M} \pm \text { SD }\end{array}$ & $\begin{array}{c}\mathbf{2 1 - 3 0} \text { years } \\
\mathbf{M} \pm \text { SD }\end{array}$ & $\begin{array}{c}\mathbf{3 1 - 4 0} \text { years } \\
\mathbf{M} \pm \text { SD }\end{array}$ & $\begin{array}{c}\mathbf{4 1 - 5 0 y e a r s} \\
\mathbf{M} \pm \text { SD }\end{array}$ & $\begin{array}{c}\mathbf{5 1 - 6 0} \text { years } \\
\mathbf{M} \pm \text { SD }\end{array}$ & $\begin{array}{c}\mathbf{6 1 - 7 0} \text { years } \\
\mathbf{M} \pm \text { SD }\end{array}$ & $\begin{array}{c}>\text { 70years } \\
\mathbf{M} \pm \text { SD }\end{array}$ \\
\hline RCCA & $52.88 \pm 7.76$ & $47.31 \pm 6.19$ & $38.89 \pm 3.57$ & $37.71 \pm 2.64$ & $32.26 \pm 3.54$ & $32.21 \pm 3.71$ & $29.67 \pm 0.91$ \\
\hline LCCA & $52.83 \pm 7.73$ & $47.32 \pm 6.21$ & $38.92 \pm 3.48$ & $37.68 \pm 2.66$ & $32.50 \pm 3.12$ & $33.35 \pm 3.96$ & $29.65 \pm 0.92$ \\
\hline $\begin{array}{l}\text { Mean } \\
\text { Total }\end{array}$ & $105.71 \pm 15.50$ & $94.64 \pm 12.40$ & $77.82 \pm 7.05$ & $75.40 \pm 5.30$ & $64.77 \pm 6.63$ & $66.57 \pm 7.67$ & $59.32 \pm 1.83$ \\
\hline RCCA & $19.04 \pm 5.18$ & $14.81 \pm 3.99$ & $15.17 \pm 4.64$ & $13.24 \pm 2.92$ & $13.30 \pm 3.58$ & $12.47 \pm 4.82$ & $10.80 \pm 1.07$ \\
\hline LCCA & $19.16 \pm 5.18$ & $14.84 \pm 4.00$ & $15.20 \pm 4.65$ & $13.46 \pm 2.92$ & $13.23 \pm 3.54$ & $12.46 \pm 5.02$ & $10.97 \pm 0.98$ \\
\hline $\begin{array}{l}\text { Mean } \\
\text { Total }\end{array}$ & $38.20 \pm 10.36$ & $29.65 \pm 7.98$ & $30.37 \pm 9.29$ & $26.71 \pm 5.84$ & $26.54 \pm 7.12$ & $24.94 \pm 9.84$ & $21.77 \pm 2.06$ \\
\hline
\end{tabular}

RCCA: Right common carotid artery.

LCCA: Left common carotid artery.

PSV: Peak systolic velocity.

EDV: End diastolic velocity.

Table 5: Mean CCA and ICA PSV and EDV of different age groups females

\begin{tabular}{|l|c|c|c|c|c|c|c|}
\hline PSV $(\mathbf{c m} / \mathbf{s})$ & $\begin{array}{c}\leq \mathbf{2 0 y e a r s} \\
\mathbf{M} \pm \text { SD }\end{array}$ & $\begin{array}{c}\mathbf{2 1 - 3 0} \text { years } \\
\mathbf{M} \pm \text { SD }\end{array}$ & $\begin{array}{c}\mathbf{3 1 - 4 0} \text { years } \\
\mathbf{M} \pm \text { SD }\end{array}$ & $\begin{array}{c}\text { 41-50years } \\
\mathbf{M} \pm \text { SD }\end{array}$ & $\begin{array}{c}\mathbf{5 1 - 6 0} \text { years } \\
\mathbf{M} \pm \text { SD }\end{array}$ & $\begin{array}{c}\text { 61-70 years } \\
\mathbf{M} \pm \text { SD }\end{array}$ & $\begin{array}{c}>70 y e a r s \\
\mathbf{M} \pm \text { SD }\end{array}$ \\
\hline & & & & & & & \\
\hline RCCA & $47.38 \pm 7.50$ & $46.19 \pm 6.80$ & $39.63 \pm 3.36$ & $37.26 \pm 3.20$ & $30.98 \pm 3.17$ & $32.90 \pm 3.33$ & $29.60 \pm 0.00$ \\
\hline LCCA & $47.48 \pm 7.32$ & $46.17 \pm 6.80$ & $39.60 \pm 3.36$ & $37.18 \pm 3.42$ & $31.02 \pm 3.11$ & $32.86 \pm 3.31$ & $29.60 \pm 0.00$ \\
\hline Mean total & $94.86 \pm 14.83$ & $92.36 \pm 13.61$ & $79.23 \pm 6.73$ & $74.45 \pm 6.62$ & $62.00 \pm 6.27$ & $65.77 \pm 6.65$ & $59.20 \pm 0.00$ \\
\hline EDV $(\mathbf{c m} / \mathbf{s})$ & & & & & & & \\
\hline RCCA & $14.81 \pm 3.97$ & $14.09 \pm 4.28$ & $14.50 \pm 3.88$ & $11.45 \pm 2.14$ & $11.25 \pm 4.45$ & $14.48 \pm 4.28$ & $7.80 \pm 0.00$ \\
\hline LCCA & $14.95 \pm 3.98$ & $14.19 \pm 4.25$ & $14.50 \pm 3.91$ & $11.33 \pm 1.86$ & $11.48 \pm 4.33$ & $14.87 \pm 4.67$ & $8.00 \pm 0.00$ \\
\hline Mean total & $29.76 \pm 7 . .95$ & $28.21 \pm 8.52$ & $29.00 \pm 7.80$ & $22.78 \pm 3.99$ & $22.73 \pm 8.87$ & $29.35 \pm 8.92$ & $15.80 \pm 0.00$ \\
\hline
\end{tabular}

RCCA: Right common carotid artery.

LCCA: Left common carotid artery.

PSV: Peak systolic velocity.

EDV: End diastolic velocity

Table 6: Overall range and means of average CCA and ICA flow velocity

\begin{tabular}{|c|c|c|c|}
\hline Variable & Simple size $(\mathbf{N})$ & Range & Mean $( \pm$ SD) \\
\hline AVFs $(\mathrm{cm} / \mathrm{sec})$ & & & \\
\hline Carotid Arteries & & & \\
\hline RCCA $_{\text {PSV }}$ & 400 & $24.00-55.43$ & $37.56 \pm 7.18$ \\
\hline RCCA $_{\text {EDV }}$ & 400 & $10.23-28.77$ & $17.03 \pm 3.88$ \\
\hline $\mathbf{L C C A}_{\text {PSV }}$ & 400 & $24.37-55.43$ & $37.56 \pm 7.16$ \\
\hline LCCA $_{\text {EDV }}$ & 400 & $10.30-28.83$ & $17.09 \pm 3.87$ \\
\hline
\end{tabular}

SD: standard deviation; CCA: common carotid artery; RCCA: right common carotid artery; LCCA: left common carotid artery; psv: peak systolic velocity; edv: end diastolic velocity.

AVFs: average flow velocities.

Table 7: Mean PSV and EDV of the Right and left Carotid arteries

\begin{tabular}{l}
\multicolumn{1}{c}{ Artery } \\
\hline
\end{tabular}


Table 8: Average mean CCA and ICA blood velocities of different age group

\begin{tabular}{|c|l|l|l|l|l|c|}
\multicolumn{1}{c}{ Vessel } & \multicolumn{1}{c}{ Age (years) } & \multicolumn{1}{c}{ P } & PSV $(\mathbf{c m} / \mathbf{s e c})$ & \multicolumn{1}{c}{ P value } & EDV $(\mathbf{c m} / \mathbf{s e c})$ & P value \\
\hline RCCA & $18-50$ & 320 & $40 \pm 6.30$ & $\mathrm{P}<0.001$ & $25 \pm 3.80$ & $\mathrm{P}<0.001$ \\
\hline & $51-81$ & 80 & $29 \pm 3.20$ & & $20 \pm 3.30$ & \\
\hline LCCA & $18-50$ & 320 & $40 \pm 6.30$ & $\mathrm{P}<0.001$ & $18 \pm 3.70$ & $\mathrm{P}<0.001$ \\
\hline & $51-81$ & 80 & $29 \pm 3.20$ & & $15 \pm 3.80$ & \\
\hline
\end{tabular}

RCCA: Right common carotid artery, LCCA: Left common carotid artery

PSV: Peak systolic velocity, EDV-End diastolic velocity.

Table 9: Average mean CCA and ICA blood velocity for males and females.

\begin{tabular}{|l|c|c|c|c|c|c|}
\hline Vessel & Sex & N & PSV $(\mathrm{cm} / \mathrm{sec})$ & $\mathrm{P}$ value & EDV $(\mathrm{cm} / \mathrm{s})$ & $\mathrm{P}$ value \\
\hline RCCA & $\mathbf{M}$ & 239 & $38 \pm 3.70$ & $\mathrm{P}=0.275$ & $24 \pm 4.40$ & $\mathrm{P}=0.89$ \\
\hline & $\mathbf{F}$ & 161 & $37 \pm 6.90$ & & $23 \pm 4.00$ & \\
\hline LCCA & $\mathbf{M}$ & 239 & $38 \pm 7.30$ & $\mathrm{P}=0.272$ & $17 \pm 0.40$ & $\mathrm{P}=0.83$ \\
\hline & $\mathbf{F}$ & 161 & $37 \pm 6.90$ & & $17 \pm 0.40$ & \\
\hline
\end{tabular}

RCCA: Right common carotid artery, LCCA: Left common carotid artery

PSV: Peak systolic velocity, EDV-End diastolic velocity.

M: males.

F: females.

Table 10: Mean total PSV verses BMI.

\begin{tabular}{|c|c|c|}
\hline BMI & Males & Females \\
\hline & CCA $(\mathbf{M} \pm$ SD) & CCA $(\mathbf{M} \pm$ SD) \\
\hline Under weight & $43.73 \pm 6.3$ & $44.35 \pm 4.77$ \\
\hline Normal weight & $41.26 \pm 8.41$ & $42.35 \pm 7.84$ \\
\hline Over weight & $36.45 \pm 5.02$ & $35.72 \pm 5.37$ \\
\hline
\end{tabular}

Table 11: Mean total EDV verses BMI

\begin{tabular}{|l|c|c|}
\hline BMI & Males & Females \\
\hline & $\mathbf{C C A}(\mathbf{M} \pm$ SD $)$ & $\mathbf{C C A}(\mathbf{M} \pm$ SD $)$ \\
\hline Under weight & $14.81 \pm 3.76$ & $16.58 \pm 4.90$ \\
\hline Normal weight & $14.76 \pm 4.44$ & $13.59 \pm 3.95$ \\
\hline Overweight & $13.98 \pm 4.48$ & $12.61 \pm 4.47$ \\
\hline
\end{tabular}

\section{Discussion}

Measurement of cerebral blood flow is an important parameter in the diagnosis and followup of cerebrovascular disease. ${ }^{7}$ Several studies have demonstrated the normal dimensions of CCA arteries ${ }^{8,9,10}$ and their flow velocities in normal adults. ${ }^{11,12}$ Thomas et al $^{13}$ found that the normal CCA PSV was $<100 \mathrm{~cm} / \mathrm{sec}$ and EDV was < $40 \mathrm{~cm} / \mathrm{sec}$. Vivian et $\mathrm{al}^{11}$ observed a trend in PSV along the course of the CCA; The more distal the measurement, the lower the velocity. The average PSV $( \pm$ SD) in the distal CCA $(75.20 \mathrm{~cm} / \mathrm{sec} \pm$ 2.37) was significantly lower than that in the proximal CCA $(86.90 \mathrm{~cm} / \mathrm{sec} \pm 25.6)(\mathrm{P}<0.001)$. This study has observed that the range of peak systolic velocity (PSV) in CCA was $24.00 \mathrm{~cm} / \mathrm{sec}-$ $55.43 \mathrm{~cm} / \mathrm{sec}$ and EDV was $10.23 \mathrm{~cm} / \mathrm{sec}-$ $28.77 \mathrm{~cm} / \mathrm{sec}$.In both measurements, the PSV and
$\mathrm{EDV}$ in CCA were $<110 \mathrm{~cm} / \mathrm{sec}$ and $<40 \mathrm{sec} / \mathrm{sec}$ respectively which agree with the findings of Brian et al and Vivian et al. This study also observed a trend in PSV along the course of the CCA. The more distal the measurement the lower the velocity which therefore collaborated with the study by Vivian et al. ${ }^{11}$ However, the mean $\mathrm{PSV} \pm \mathrm{SD}$ of the CCA $(33.80 \mathrm{~cm} / \mathrm{sec} \pm 6.60)$ and the proximal CCA $(41.30 \mathrm{~cm} / \mathrm{sec} \pm 8.10)$ when compared to the findings of Vivian et al, distal CCA $(75.20 \mathrm{~cm} / \mathrm{sec} \pm 23.70)$ and proximal CCA $(86.90 \mathrm{~cm} / \mathrm{sec} \pm 25.60)$ tend to be lower in this study. This may be due to differences in equipment or physiologic factors such as cardiac output $^{14}$ or even geographical differences and standard of living between the two populations studied. 
The variability of velocities along the course of the CCA may be a result of several factors. Laminar flow within a rigid tube is governed by the law of conservation of momentum. ${ }^{15}$ In the CCA however, blood flow is not laminar where the vessel is tortuous, or where it bifurcates ${ }^{16}$. Furthermore, the normal compliance of the vessel wall may serve to dampen velocities and thereby contribute to the progressive decline in velocity along the course of CCA. ${ }^{17}$

Ultrasonographic studies to ascertain the relationship between the CCA flow velocities (FVs) with age and sex were done by previous researchers. ${ }^{18}$ Burhan et $\mathrm{al}^{7}$ evaluated cerebral blood flow measurements of the extracranial carotid arteries with Doppler ultrasonography in healthy adults. They found a significant decrease in blood velocities in the CCA with increasing age. Vivian et $\mathrm{al}^{15}$ in their study on the variability of Doppler USS measurements along the common carotid artery. They found that, the PSV and EDV value in the CCA were consistently lower in the older group at all locations of measurements. This study showed an age dependent decline in all FVs of the CCAs which is in agreement with the previous studies above.

In studies where a decrease in cerebral blood flow was detected related to age, the decrease was related to a decrease in the perfusion demand of the brain, secondary to atrophy from progressive neuronal loss. ${ }^{19}$ Again increases in carotid diameter with age result in a decrease in velocity to maintain flow. ${ }^{20}$ Another important reason for the reduction in FV with age may be reduced cardiac output. $^{21}$

Burhan et $\mathrm{al}^{7}$ evaluated the relationship between CCA flow velocities with sex. They found that in females PSV and EDV in ICA were higher as compared to males however in the CCA, the difference was not significant. Hüsseyin et $\mathrm{al}^{18}$ in their study found no significant differences between females and males with respect to FV.

The effect of height, weight and BMI on carotid artery flow velocities were also evaluated by previous researchers Hüsenyin et $\mathrm{al}^{18}$ found in their study that PSV and EDV in CCA were significantly lower in the over weight than the normal individual, however, found no correlation between flow velocities of carotid arteries with height. This present study found that the FV in carotid arteries were lower in over weight individuals. The mean right PSV in CCA was 34 $\pm 6 \mathrm{~cm} / \mathrm{sec}$ in over weight and $42 \pm 8 \mathrm{~cm} / \mathrm{sec}$ in normal individuals $(\mathrm{p}=0.000)$. The mean right EDV in CCA was $23 \pm 4 \mathrm{~cm} / \mathrm{sec}$ in over weight and $26 \pm 5 \mathrm{~cm} / \mathrm{sec}$ in normal individuals. No correlation between carotid arteries flow velocities with height was found $(r=0.036 ; p=0.5)$. The present study showed agreement with the finding above.

\section{Conclusion}

Established values of the flow velocities will serve as reference points in our environment and will equally add to the pool of literature available for academic and research references.

\section{Acknowledgments}

We sincerely appreciate all the volunteers in this study.

\section{References}

1. Muizelaar JP, Marmarou A, DeSalles AA, et al. Cerebral blood flow and metabolism in severely head injured children, part 1: relation with GCS score, outcome, ICP and PVI. J Neurosurg 1989; 71:63.

2. Muizelaar JP, Fatouros PP, Schroder ML. A new method for quantitative regional cerebral blood volume measurements using computed tomography. Stroke 1997; 28:1998.

3. Ramazan A, Bumin D, Murat A, et al. Doppler Sonography Evaluation of Flow Velocity and Volume of the Extracranial Internal Carotid and Vertebral Arteries in Healthy Adults. Inc. J Clin Ultrasound 2007; 35:27-33.

4. Rahman R A, Azran A. Flow Velocity in Common Carotid Artery. At 
https://www.intechopen.com/books/carotid -artery-gender-and-health/flow-velocityin-common-carotid-artery Accessed on 15/12/09.

5. Mira L, Katz M. Carotid duplex imaging 2009. At gehealhcare.com Accessed on 12/11/09

6. Paul S S. Ultrasound of the carotid and vertebral arteries. British medical Bulletin 2000; 56:346-366.

7. Burhan Y, Besir E, Ali T. Cerebral blood flow measurements of the extracranial carotid and vertebral arteries with Doppler ultrasonography in healthy adults. TSR 2009; 15(4): 1305-3825.

8. Jaroslaw K, Michal A, Scott E, et al. Carotid artery diameter in men and women and the relation to body and neck size. Stroke 2006; 37:1103-1105.

9. Kerstin J-U, Mats J-U, Jan J. Carotid artery diameter correlates with risk factors for cardiovascular disease in a population of 55-year old subjects. Stroke 1999; 30:1572-1576.

10. Denarie M, Gariepy J, Chironi G, et al. Distribution of ultrasonographyicallyassessed dimension of common carotid arteries in healthy adults of both sexes. Science Direct 2000; 148:297-302.

11. Vivian SL, Barbura S, Hertzberg, et al Assessment of stenosis: implications of variability of Doppler measurements in normal appearing carotid arteries. Radiology 1999;212:493-498.

12. Homma S, Hirose $\mathrm{N}$, Ishida $\mathrm{H}$ et al. Carotid plaque and intima-media thickness assessed by B-mode ultrasonography in subjects ranging from young adults to centenarians. Stroke 2001; 32:830-835.

13. Thomas FG, Benjamin F. carotid artery stenosis $1994 . \quad$ At brighamrad.harvardedu/education/online/tc d.html. Presentation.
14. Zwiebel W. New Doppler parameters for carotid stenosis. Semin ultrasound CT MR 1997;18:66-67.

15. Vivian S, Barbara S, Hertzberg MJ, et al. Variability of Doppler US measurements along the common carotid artery: Effects on estimates of internal carotid arterial stenosis in patients with angiographically proved disease.

16. Steinke W, Kloetzsch C, Hennerici M. Variability of flow patterns in the normal carotid bifurcation. Artherosclerosis 1990; 84:121-127.

17. Mayer JI, Khalil RM, Obuchowski NA, Baus LK. Common carotid artery variability of Doppler ultrasound velocity measurements. Radiology 1997; 204:339341.

18. Hüseyin O, Hakan A, Selami S, Erkin O. Effects of overweight on luminal diameter, flow velocity and intima-media thickness of carotid arteries. TSR 2006; 12:142-146.

19. Secheel P, Ruge C, Schoning M. Flow velocity and flow volume measurements in the extracranial adults: reference data and the effects of age. Ultrasound Med Biol 2000; 26:1261-1266.

20. Polak JF, Kronmal RA, Tell GS, et al. Compensatory increase in common carotid artery diameter-Relation to blood pressure and artery intima-media thickness in older adults. Stroke. 1996; 27:2012-2015.

21. Guyton A. Regulation of cardiac output. In Guyton A. Anesthesiology, 11th ed. Elservier Saunders Philadelphia, Pensylvanian, 2006; pp: 241-242. 